\title{
Ameloblastic Secretion and Calcification of the Enamel Layer in Shark Teeth
}

\author{
NORMAN E. KEMP \\ Division of Biological Sciences, The University of Michigan, Ann Arbor, \\ Michigan 48109
}

\begin{abstract}
Tooth primordia at early stages of mineralization in the sharks Negaprion brevirostris and Triaenodon obesus were examined electron microscopically for evidence of ameloblastic secretion and its relation to calcification of the enamel (enameloid) layer. Ameloblasts are polarized with most of the mitochondria and all of the Golgi dictyosomes localized in the infranuclear end of the cell toward the squamous outer cells of the enamel organ. Endoplasmic reticular membranes and ribosomes are also abundant in this region. Ameloblastic vesicles bud from the Golgi membranes and evidently move through perinuclear and supranuclear zones to accumulate at the apical end of the cell. The vesicles secrete their contents through the apical cell membrane in merocrine fashion and appear to contribute precursor material both for the basal lamina and the enameline matrix. The enamel layer consists of four zones: a juxta-laminar zone containing newly polymerized mineralizing fibrils (tubules); a pre-enamel zone of assembly of matrix constituents; palisadal zones of mineralizing fibrils (tubules); and interpalisadal zones containing granular amorphous matrix, fine unit fibrils, and giant cross-banded fibers with a periodicity of $17.9 \mathrm{~nm}$. It seems probable that amorphous, non-mineralizing fibrillar and mineralizing fibrillar constituents of the matrix are all products of ameloblastic secretion. Odontoblastic processes are tightly embedded in the matrix of the palisadal zones and do not appear to be secretory at the stages investigated. The shark tooth enamel layer is considered homologous with that of other vertebrates with respect to origin of its mineralizing fibrils from the inner dental epithelium. The term enameloid is appropriate to connote the histological distinction that the enamel layer contains odontoblastic processes but should not signify that shark tooth enamel is a modified type of dentine. How amelogenins and/or enamelins secreted by ameloblasts in the shark and other vertebrates are related to nucleation and growth of enamel crystallites is still not known.
\end{abstract}

Like the teeth of all gnathostomes, those of sharks develop from epithelial evaginations of the dental lamina surmounting ectomesenchymal dental papillae (Gaunt and Miles, '67). As a tooth bud elongates, its epithelium heightens by differentiation of columnar ameloblasts, and beneath these a layer of odontoblasts differentiates at the periphery of the dental papilla (Kerr, '55; Moss, '70, '77; Kemp and Park, '74; Kerebel et al., '77; Samuel et al., '83). Matrix of the enamel layer first accumulates at the tip of the tooth between ameloblasts and odontoblasts and then extends over the whole crown (Kerr,
'55). Shortly after the enameline matrix appears, it begins to calcify by deposition of hydroxyapatite crystallites. Although the cell bodies of odontoblasts become increasingly separated from the ameloblasts by accumulation of this mineralizing matrix, they nevertheless extend odontoblastic processes which remain embedded in the enameline matrix and become longer as the parent odontoblasts recede farther from the epithelium. After calcification of the enamel layer is well under way, deposition and calcification of the collagenous matrix of dentine ensues. 
It is the presence of odontoblastic processes within the enamel layer of sharks' teeth which accounts for the long-standing controversy about the homology of the tooth enamel layer in elasmobranchs and higher vertebrates. Is the enameline matrix a product of the overlying ameloblasts as in mammals, or rather of the odontoblasts and their penetrating odontoblastic processes; or is it a product of both cell layers? As stated earlier (Kemp and Park, '74), "the case for the homology of enamel in elasmobranchs rests squarely on the question of the origin of the organic matrix." Each of these possibilities has had its cadre of supporters (Kemp and Park, '74; Moss, '77; Schaeffer, '77). If the enameline matrix of shark teeth is ameloblastic in origin, we may conclude that it is homologous to that of mammalian teeth. If it is secreted by odontoblasts, it is actually a specialized type of dentine. If, however, it is a product of both cell types, it is different from either enamel or dentine in mammals. The term enameloid, introduced by Poole ('67) and $\emptyset \mathrm{r}$ vig ('67), is commonly used in reference to the enamel layer of lower vertebrates but leaves open a decision on which cell layers produce its mineralizing matrix.

Mammalian ameloblasts secrete matrix proteins called amelogenins and enamelins (Graver et al., '78; Termine et al., '80; Fincham et al., '82a,b, '83; Slavkin et al., '82; Belcourt et al., '83; Robinson et al., '83; Zeichner-David et al., '83) which control nucleation and growth of the relatively large hexagonal crystallites of enamel (Kerebel et al., '79; Arends et al., '83). Odontoblasts, on the other hand, secrete a collagenous matrix which fosters development of the smaller mineral crystallites characteristic of dentine (Glimcher, '81). By using fluorescent antibodies to bovine amelogenin, Herold et al. ('80) and Slavkin et al. ('83b) have demonstrated that shark tooth ameloblasts synthesize an enamel-like protein. Similarly with antibodies to mouse amelogenins Slavkin et al. ('83a) have shown that hagfish tooth epithelium evidently secretes the same type of protein. Enamel proteins evolved early in vertebrate phylogeny and apparently have not changed markedly up to the present (Slavkin et al., '83a, '84; Kemp, '84). Shark tooth dentine closely resembles mammalian dentine in the relationship between collagen fibrils and mineral crystallites (Garant, '70; Kemp and Park, '74). Dentine as a type of mineralized tissue appears to be unequivocally homologous in all vertebrate groups (Kemp, '84).
To prove homology of the enamel layers of elasmobranchs and mammals, it would be necessary to demonstrate that elasmobranch ameloblasts actually secrete their amelogenin-enamelin-like proteins into the enameline matrix and that these proteins order development of enamel crystallites as in mammalian teeth. That shark tooth ameloblasts are indeed secretory has been demonstrated (Mörnstad, '74; Kemp, '74a,b; Kemp and Park, '74; Kerebel et al., '77; Nanci et al., '83; Samuel et al., '83). Furthermore, it has been shown that crystallites of the shark tooth enamel layer grow to be large and hexagonal like those of mammalian enamel (Poole and Gillett, '69; Kemp and Park, '74). How the secretory product of ameloblasts is related to the pattern of mineralization of the enamel of shark's teeth in comparison to those of other vertebrates is the focus of this paper.

\section{MATERIALS AND METHODS}

Developing teeth from two shark species, the lemon shark Negaprion brevirostris and the whitetip shark Triaenodon obesus, were examined in this investigation. Rectangular blocks the width of a single file of teeth were excised from the jaws of a $40-\mathrm{cm}$ specimen of Negaprion collected by Dr. I. Kaufman Arenberg at the Lerner Laboratory, Bimini, Bahamas. Similar blocks were excised from a 120-cm specimen of Triaenodon collected at the Enewatak Marine Biological Laboratory, Enewatak Atoll, Marshall Islands. Negaprion tissue was fixed in 5\% glutaraldehyde buffered at $\mathrm{pH} 7.4$ with shark phosphate buffer (Long et al., '68), that of Triaenodon in $6.25 \%$ glutaraldehyde buffered at $\mathrm{pH} 7.4$ with $0.1 \mathrm{M}$ phosphate buffer. Fixed tissue was transported to Ann Arbor and stored in the fixative in a refrigerator at $10^{\circ} \mathrm{C}$ for a month to two years before further processing.

Preparation for transmission electron microscopy was continued by severing the oral mucosa with attached teeth from the block of jaw skeleton, washing with $0.1 \mathrm{M}$ phosphate buffer, and post-fixing in ice-cold $1 \% \mathrm{OsO}_{4}$ in the same buffer at $\mathrm{pH}$ 7.4. Fixed files of teeth were dehydrated in a graded series of ethanols, cleared in propylene oxide, and embedded in Epon 812 in flat containers. After polymerization at $60^{\circ} \mathrm{C}$ the tooth files were cut from the flat block and mounted in a slot at the end of a round stub of Epon previously polymerized in a size- 00 gelatin capsule. Tissue was oriented and trimmed so that young, newly calcifying teeth at the posterior end of 
a tooth file were exposed for sectioning. Thin sections were cut with a diamond knife on an LKB Ultratome and mounted on 200-mesh copper grids. They were stained with uranyl acetate and lead citrate, and micrographs were taken with an RCA EMU-3E electron microscope operating at $50 \mathrm{kV}$.

\section{RESULTS \\ Morphology of ameloblasts}

Tooth primordia of Negaprion described in the present investigation were from the most posterior row showing visible mineralization. Before osmication these young teeth were white at the tip, but they became blackened after osmication. At this stage calcification was in progress in the tooth tip and also around the sides (collar) of the tooth in the enamel layer; however, differentiation of ameloblasts and of underlying organic matrix was still under way. Tooth sections showed an inner dental epithelium of columnar ameloblasts surrounding the enamel (enameloid) matrix covering the dental papilla. At this stage the enamel organ also includes two layers of squamous epithelial cells enclosing the ameloblasts, namely, the stratum intermedium and outer dental epithelium (Fig. 1).

Nuclei of cells in both outer dental epithelium and stratum intermedium are flattened so that in cross section they appear elongated circumferentially around the tooth. Nuclei of the ameloblasts, on the other hand, are oriented radially with respect to the long axis of the tooth. Heterochromatin is concentrated along the nuclear membranes and in irregular patches within the nucleoplasm of cells in all three layers of the enamel organ. Mitochondria and endoplasmic reticular membranes are widely dispersed in cells of the intermediate layer, but these organelles are largely eliminated and only a thin rim of cytoplasm remains in the outer dental epithelium.

The border between ameloblasts and intermediate cells is distinguished by peg-like protrusions of the ameloblasts (Figs. 1,2). Elsewhere along this border gap junctions and occasional desmosomes bind ameloblasts to overlying cells. Lateral borders of ameloblasts at levels basal to the nucleus are bound by gap junctions and occasional desmosomes, and also tight junctions near their outer ends (Figs. 1, 3). Cell membranes may be separated enough to allow outgrowth of short, microvillous processes (Fig. 1).
The elongated nuclei of secretory ameloblasts lie approximately midway along the length of the cell. Cytoplasmic morphology is polarized so that the infranuclear (proximal or basal) end is preferentially endowed with organelles indicative of protein synthesis and production of secretory vesicles-mitochondria, Golgi dictyosomes, endoplasmic reticular membranes, and ribosomes. From the standpoint of ameloblastic function this polarization of synthetic machinery is important, for it indicates that it is in this region where the ameloblastic vesicles destined for secretion are produced. Such vesicles, apparently budded off from the Golgi membranes, are abundant in the infranuclear zone (Figs. 2-4).

Nuclei of ameloblasts have prominent nucleoli (Fig. 5), indicating that they have the potential for synthesis of ribosomal RNA. Perinuclear cytoplasm contains cisternae and vesicles of endoplasmic reticulum as well as ribosomes and occasional mitochondria, but no Golgi elements. Intercellular boundaries at nuclear levels are characterized predominately by smooth gap junctions with occasional desmosomes. There is also some protrusion and interdigitation of cell processes at this level (Fig. 5).

Apical to the nucleus the supranuclear cytoplasm (Fig. 6) resembles that of the perinuclear region. Endoplasmic reticulum and ribosomes are abundant, but mitochondria are scarce and Golgi elements are missing. Moderate interdigitation of cell membranes continues for some distance apical to the nucleus, but the degree of interdigitation progresses still more apically to the extent that long, microvillous processes become interpenetrated like interlocking fingers (Figs. 6, 7, 9).

Bordering the basal lamina, the cell membrane at the apical end of ameloblasts is irregularly folded (Figs. 7-10). Depressions between surface folds are sac-like invaginations which appear round or oval in cross section (Fig. 9) and enclose inward extensions of the basal lamina. Gaps between the apical ends of ameloblasts are also filled with basal lamina material (Fig. 10). Since components of the basal lamina are considered to be derived chiefly from epithelial cells, distribution of the lamina probably reveals the extent of ameloblastic surface participating in secretion of ameloblastic products. Enlargement of the basal lamina shows that its lamina densa is granular and variable in thickness (Fig. 8). Granular and filamentous 

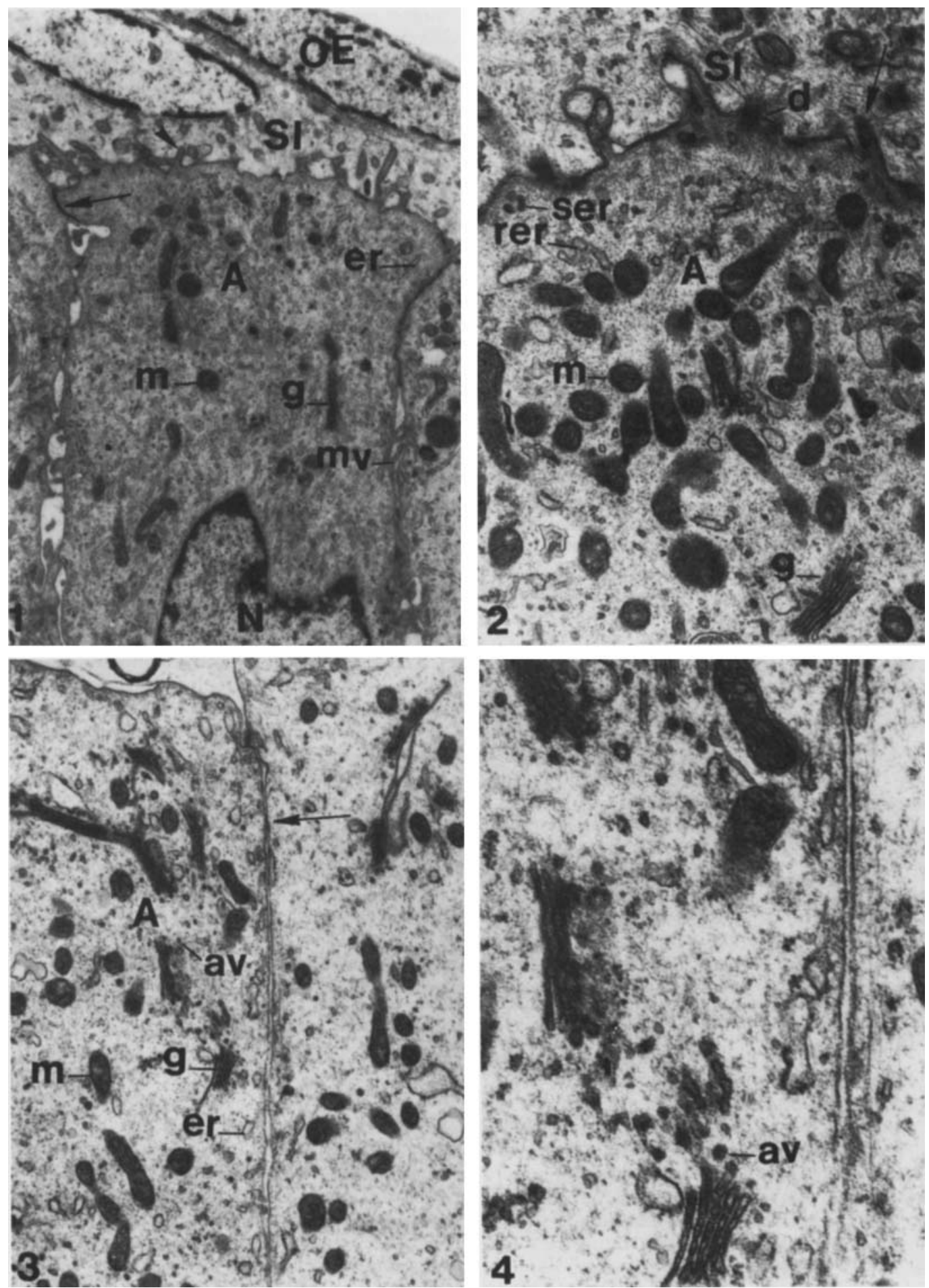
components of enameline matrix make direct contact with the under side of the basal lamina.

Secretory ameloblastic vesicles accumulate toward the apical end of an ameloblast and may become clustered near the cell membrane (Fig. 10). Secretion is accomplished in the usual merocrine fashion, i.e., by fusion of a vesicle to the cell membrane, rupture, and discharge of vesicular contents. Materials for the basal lamina and for transport through it into the enameline matrix are thus made available.

As tooth primordia begin to mineralize, they flatten antero-posterially and the base expands laterally; thus in cross section they are lens-shaped. Around the angle at the lateral border of a tooth the ameloblasts appear to be stretched in their supranuclear zones so that they are not highly interdigitated (Fig. 10), in contrast to ameloblasts surrounding more medial portions of the tooth rim where interdigitation is extensive (Figs. 7,9). Moreover, the apical cytoplasm of these more lateral ameloblasts appears to contain more

Figs. 1-14. Electron micrographs of dental epithelium and underlying enameline matrix in cross sections of teeth of Negaprion brevirostris (Figs. 1-13) and Triaenodon obesus (Fig. 14).

Fig. 1. Ameloblasts (A), oriented perpendicular to tooth surface, are covered by squamous cells of stratum intermedium (SI) and outer dental epithelium (OE). Peglike protrusions of ameloblasts penetrate cortex of intermediate cells (arrowhead). Baso-lateral ends of ameloblasts adhere closely (arrow), but lateral cell borders may be separated by intercellular spaces into which short microvilli (mv) extend. The infranuclear zone of cytoplasm basal to the nucleus $(\mathrm{N})$ contains abundant mitochondria (m), Golgi dictyosomes (g), and profiles of both rough and smooth endoplasmic reticulum (er). $\times 7,330$.

Fig. 2. Infranuclear cytoplasm of ameloblast (A) and adjacent cell of stratum intermedium (SI). Peg-like protrusions of ameloblasts (arrow) stud surface and enhance adhesion to SI cells. Junctions between cells are gap junctions and occasional desmosomes (d). m, mitochondrion; g, Golgi dictyosome; rer, cisterna of rough endoplasmic reticulum; ser, vesicle of smooth endoplasmic reticulum. $\times 20,035$

Fig. 3. Infranuclear cytoplasm of two adjacent ameloblasts (A) showing generally smooth gap junctions along their borders and a tight junction toward basal surface (arrow). $\times 13,360$.

Fig. 4. Enlarged view of Golgi regions in Figure 3, showing accumulation of ameloblastic vesicles (av), apparently budded from Golgi dictyosomes. $\times 13,030$. secretory ameloblastic vesicles than does that of highly interdigitated cells (cf. Figs. 9, 10). These differences-less interdigitation and more accumulated vesicles-suggest that the lateral ameloblasts are at an earlier stage of ameloblastic secretion than are more medial ones. Highly interdigitated cells like those illustrated in Figures 7 and 9 may be beyond the peak of ameloblastic secretion and may have lost cell volume as a result of considerable secretion. Interdigitation may be a response to decreased volume of the supra. nuclear zone, analogous to the change in shape of an accordion from its relatively smooth inflated shape to its highly pleated deflated shape.

\section{Morphology of enameline matrix}

Beneath the basal lamina is the enameline matrix, which can be subdivided into four zones (Figs. 7, 9): Immediately under the lam. ina is a juxta-laminar zone of granules and fibrils which have begun to mineralize by deposition of accompanying hydroxyapatite crystallites. Below this narrow calcifying zone is a non-calcified zone of pre-enamel, which seems to be an assembly area for the precursor materials of the two deeper-lying zones, the mineralized palisades (Garant, '70), and the non-mineralized interpalisadal zones.

Granular material of the enameline matrix is in direct continuity with the granular substance of the basal lamina (Fig. 8) and thus gives the latter an irregular contour. This morphology supports the view that the amorphous granular component of the juxta-laminar zone is derived from materials which migrate through the basal lamina from its outer to its inner side. Fibrillogenesis of mineralizing fibrils evidently begins almost as soon as precursor materials breach the basal lamina, for such fibrils are often attached to the lamina. In fact, the fibrils sometimes appear anchored in the basal lamina (Fig. 8) as though polymerization of fibrils had begun even before precursor substance had completed its passage through the membrane. Primordia of the giant, cross-banded fibers which develop within the pre-enamel and interpalisadal zones may also attach directly to the under side of the basal lamina. Crystallogenesis of enamel crystallites begins early in fibrillogenesis, for mineralizing fibrils contacting the basal lamina or embedded in it may already be accompanied by crystallites (Figs. 7, 8). 

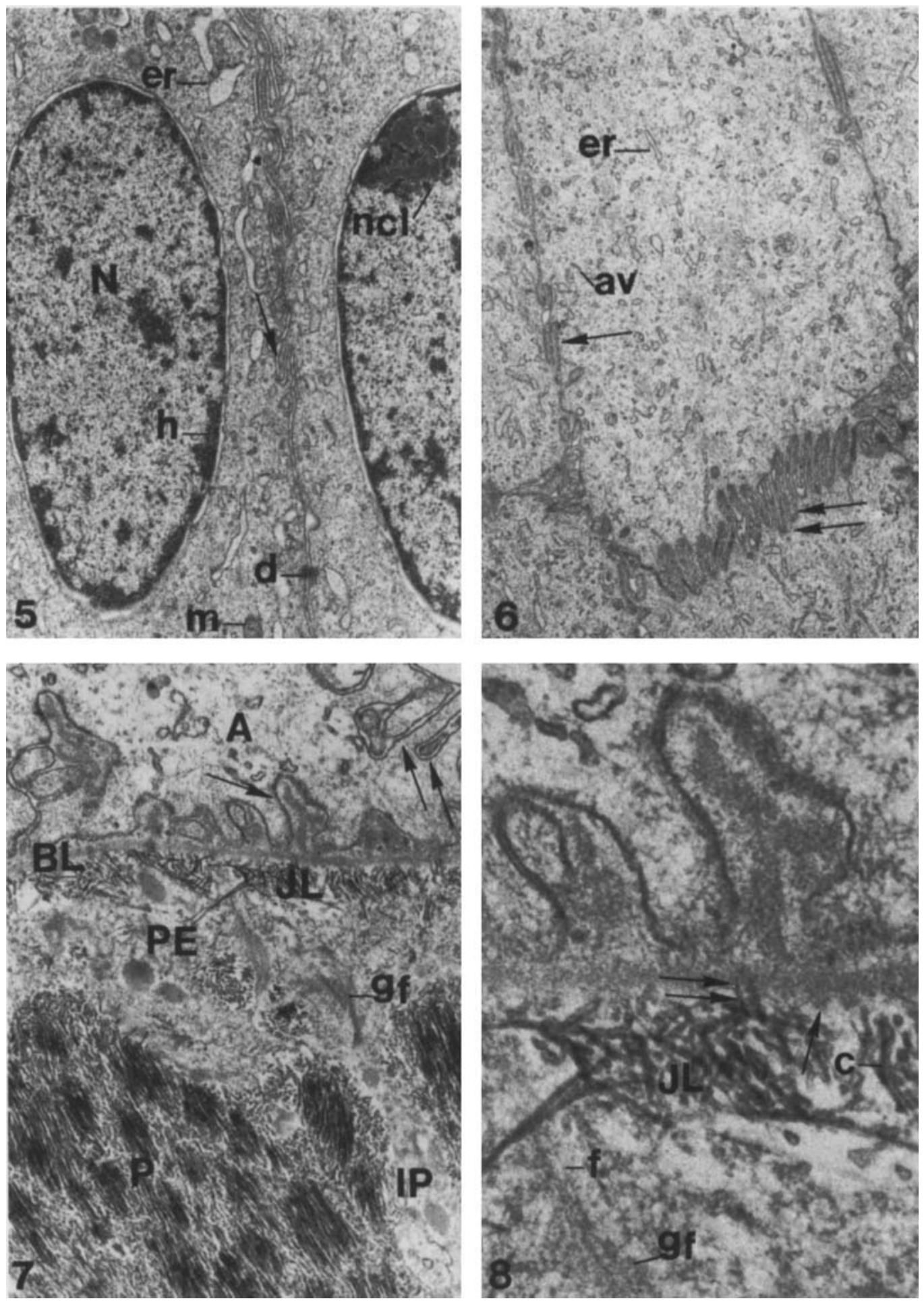
Within the pre-enamel zone there are amorphous granular material, fine non-mineralizing filaments called "unit fibrils," and primordia of the large banded fibers called "giant fibres" (Kemp and Park, '74). Also in this zone there are clusters of mineralizing fibrils which appear to be emigrating toward the mineralizing palisades (Figs. 7, 9). No collagen fibers are found in this region.

Morphology of the interpalisadal zones is similar to that of the pre-enamel zone. Amorphous material, unit fibrils, and giant fibers are present, but the latter reach their full potential for growth here. These large, unmineralized fibers have room to grow radially between the palisades and may enlarge to the full width of the space between adjacent palisades (Figs. 11, 12). As they increase either in length or girth, they recruit amorphous and fine fibrillar components of the matrix. What is most striking about these fibers is the periodicity of their banding, 17.9 $\mathrm{nm}$. It is markedly different from that of

Fig. 5. Elongated nuclei (N) of ameloblasts. Cell boundaries at this level are moderately interdigitated (arrow). h, heterochromatin; ncl, nucleolus; d, desmosome; er, cisterna of endoplasmic reticulum; m, mitochondrion. $\times 13,055$

Fig. 6. Cytoplasm at supranuclear level of ameloblasts. Here endoplasmic reticular profiles (er), including small vesicles thought to be secretory ameloblastic vesicles (av), are abundant, but mitochondria are sparse and Golgi elements absent at this level. Interdigitation of cell surfaces is moderate at levels toward nucleus (arrow) but is more pronounced (double arrow) at more apical levels. $\times 8,710$.

Fig. 7. Border between ameloblasts (A) and enamel layer matrix, consisting of juxta-laminar zone (JL) containing mineralizing fibrils, pre-enamel zone (PE), mineralizing palisades (P) and non-mineralizing in terpalisadal zones (IP). Pre-enamel zone contains amorphous granular material, fine fibrils and profiles of po lymerizing giant fibrils (gf). Apical surface of ameloblast adjoining basal lamina (BL) is extensively infolded by pocket-like invaginations (arrow) lined by basal laminar material. Apico-lateral surfaces of adjacent ameloblasts are highly interdigitated (double arrow). $\times 21,510$.

Fig. 8. Enlarged view of a portion of the border between the ameloblast (A) and enamelin matrix illustrated in Figure 7. Granular components of juxta-laminar zone (JL) make direct contact with lamina densa of basal lamina (arrow). Mineralized fibrils sometimes appear anchored in basal lamina (double arrow). Primordium of giant fiber ( $\mathrm{gf}$ ) incorporates amorphous granular material and fine, unit fibrils (f) during growth. Mineral crystallites (c) are aligned along mineralizing fibrils $\times 75,845$. collagen fibers (average $64.0 \mathrm{~nm}$ ); hence it is not likely that they are collagenous.

Except for the thin layer of mineralized fibrils in the juxta-laminar zone, sharks' teeth mineralize in blocks of matrix called palisades because of their cross-sectional resemblance to a line of promontories. Odontoblastic processes extend into the palisades from odontoblasts along the outer border of the dental papilla and are embedded tightly within the matrix of mineralizing fibrils (Fig. 11). There is no accumulation of unmineralized matrix around these processes; hence they do not appear to be secretory at the stage when mineralization is in progress. At this time they appear merely to be entrapped. Conceivably odontoblastic processes might help to organize the pattern of palisades and interpalisadal zones by providing protoplasmic cores around which enameline matrix is deposited. Since there may be sev. eral odontoblastic processes within a single palisade, however, it seems improbable that individual odontoblasts are responsible for the observed pattern. Alternatively, individual ameloblasts may impose the palisadalinterpalisadal pattern. Although there is no obvious one-to-one relation between the apical ends of ameloblasts and the palisadal blocks, the diameters of ameloblasts and palisades are similar in magnitude.

Crystallites of the enamel layer develop within the interior of fibrils, which thus are actually tubules (Kemp and Park, '74). Dense crystallites develop within electron-lucid sheaths of organic matrix (Figs. 13, 14). Some tubules appear to lack interior crystallites. Whether tubule formation is a necessary prerequisite for crystallite nucleation, or vice versa is a response to the mechanics of crys. tallite initiation, is an important, unanswered question.

Enamel crystallites in a developing tooth of the whitetip shark Triaenodon (Fig. 14) illustrate the fact that as crystallites grow they assume the hexagonal outline characteristic of apatite minerals (Kemp, '84). These of Triaenodon are from a larger and presumably older tooth primordium than those of Negaprion illustrated in Figure 13. Sheaths surround most of the Triaenodon crystallites, but these investments are either very thin or absent from the large crystallites. Apparently reduction or removal of organic matrix accompanies crystallite growth. Growing crystallites become aligned in cables, within which they are oriented in the same direc- 

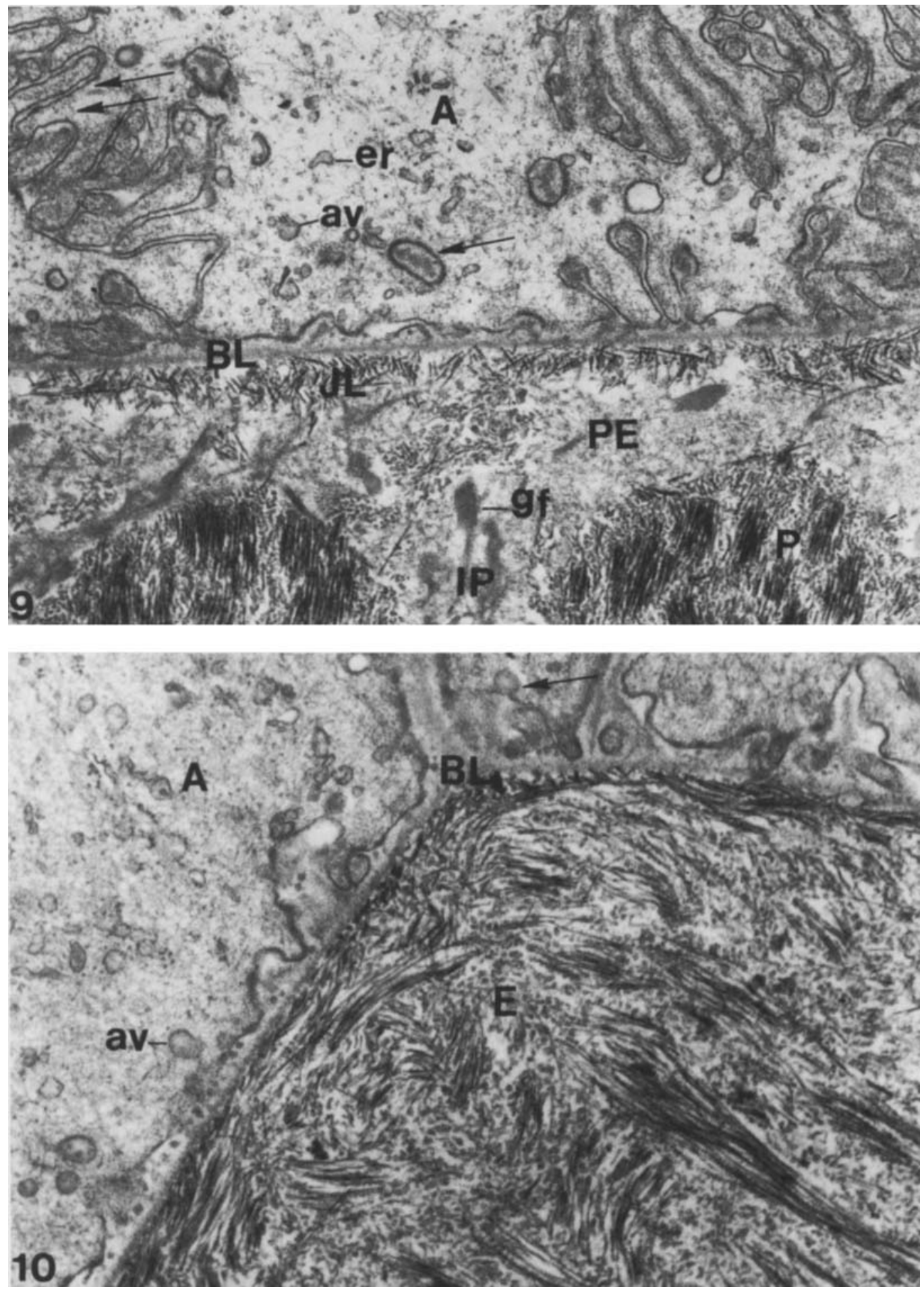
tion. The crystallites extend for long distances without breaks, but their actual lengths have not been determined. Tubules (sheaths) around the crystallites limit their growth in width while allowing extensive growth in length. How mineral and organic components interact to regulate crystallite growth is another intriguing, but unanswered question.

\section{DISCUSSION}

In the long march of time since vertebrates diverged from their protochordate ancestors (Gans and Northcutt, '83; Northcutt and Gans, '83), two separate modes of phosphatic calcification of their sclerified tissues have evolved (Kemp, '84). The first is collagenassociated mineralization exemplified by the development of relatively small, needle- or lath-shaped crystallites of hydroxyapatite aligned along collagen fibrils in calcified cartilage, bone, dentine, and cementum. The second mode is amelogenin-enamelin-associated mineralization, characterized by the development of relatively large, hexagonal crystallites of apatite within a sheath com. posed of the glycoproteins amelogenin or enamelin in the enamel (enameloid) layer of integumentary scales or teeth. Both modes were evidently utilized in development of the dermal odontodes and endoskeletal tesserae of the earliest fossil ostracoderms (Ørvig, '77; Schaeffer, '77; Kemp and Westrin, '79) and have been retained, probably with little biochemical change, throughout the course of vertebrate phylogeny (Kemp, '84).

Fig. 9. Border between ameloblasts (A) and enamel layer matrix, showing extensive interdigitation of apicolateral surfaces of adjacent cells (double arrow). Invaginations of apical surface appear in section as rounded profiles (arrow) enclosing basal laminar material. Beneath the basal lamina (BL) the enameline matrix consists of juxta-laminar zone (ЛL), pre-enamel zone (PE), palisades (P) and interpalisadal zones (IP). er, cisterna of endoplasmic reticulum; av, ameloblastic vesicle; gf, primordium of giant fiber polymerizing from amorphous and finely fibrillar matrix. $\times 22,150$.

Fig. 10. Border between ameloblasts (A) and enameline matrix (E) at lateral margin of lens-shaped cross section of tooth. Ameloblastic vesicles (av) accumulate in apical cytoplasm and fuse with cell surface (arrow) before discharging their contents extracellularly. Material of basal lamina (BL) extends into spaces between separated apical ends of ameloblasts. Basal lamina here is relatively thin, and mineralized palisadal matrix abuts directly against it; thus, juxta-laminar zone and preenamel zone (Figs. $7-9$ ) are absent. $\times 27,870$.

\section{Differentiation of ameloblasts}

During amelogenesis of mammalian teeth the ameloblasts undergo a series of morphological and functional changes from their cuboidal, preameloblastic, presecretory phase to their tall, columnar, secretory phase and then to reduced height again in their maturation phase. Reith ('67, '70) has distinguished five stages in amelogenesis of rat molar teeth: 1) secretory phase; 2) transitional stage when cells begin to diminish in height; 3) preabsorptive phase; 4) early maturation stage when organic materials are reabsorbed from the matrix; and 5) late maturation stage when water is probably resorbed from the matrix. Maturation stages of ameloblasts in rat incisor enamel development show morphological specializations indicative of resorption of organic matrix and water from maturing enamel, as well as transfer of iron pigment back into it (Kallenbach, '68). Secretory ameloblasts of mice accumulate secretion granules in their Tomes' processes (Garant and Nalbandian, '68).

Differentiating shark tooth ameloblasts pass through stages similar to those of mammalian teeth. Kerebel et al. ('77) have de. scribed three stages in development of tooth enamel in the dogfish shark Scylliorhinus canicula, applicable to three other species they studied-Prionace glauca, Squalus acanthias and Scymnorhinus lichas. At stage 1 the ameloblasts have centrally located nuclei, mitochondria are randomly distributed, and Golgi dictyosomes are localized at the basal pole of the cell. At this time the apical border of the cell adjacent to the basal lamina is smooth. At stage 2 the nucleus has shifted toward the basal end of the elongating cell and has an irregular surface contour, mitochondria have elongated, and the apical border of the cell has invaginations which increase its surface area. Secretion from the ameloblasts results in thickening of the basal lamina. At stage 3, considered to be a period of maturation, mineralization of the enamel layer is under way. Mineral crystallites first form in the matrix immediately beneath the basal lamina, but only rarely do they contact thecollagenfibers which project into the enameline matrix from its inner side adjacent to odontoblasts. Collagen fibers extending into the developing enameline layer diminish as maturation proceeds.

According to the description of Kerebel et al. ('77), ameloblasts differentiate in basal- 

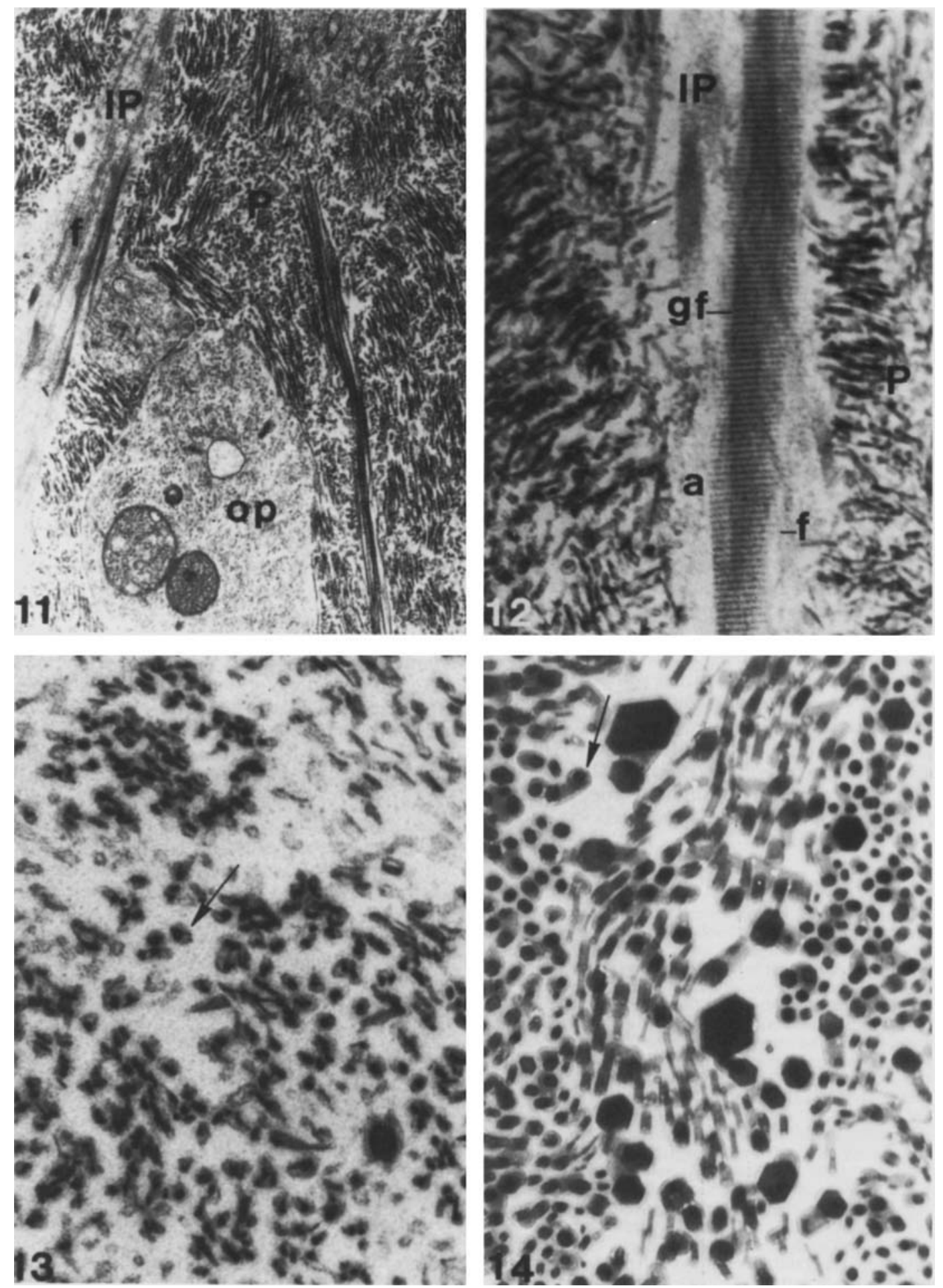
coronal sequence as tooth primordia elongate. Those toward the broad base of a mineralizing tooth bud are in stage 1 , those somewhat higher in stage 2, and those over the rest of the crown of the tooth in stage 3. Although ameloblasts at the latter stage are perhaps beyond their period of most active secretion, they still contain secretory ameloblastic vesicles and are probably still secreting them. Ameloblasts described in this investigation were at Kerebel stage 3 , although those around the lateral edge of a developing tooth were evidently at a younger stage than those over the flattened surfaces. In Negaprion the ameloblasts show characteristic features of secretory cells-polarization of cytoplasmic organelles, accumulation and secretion of ameloblastic vesicles, and cell surface changes which include lateral interdigitations and apical invaginations.

\section{Enamel versus enameloid}

The term enameloid was originally introduced to distinguish the tooth cap of lower vertebrates from the ectodermally derived "true enamel" of reptiles and mammals (Poole, '67; Ørvig, '67), because it was controversial whether the outer tooth layer of fishes and amphibians was derived from ameloblasts or was a modified type of dentine derived from mesenchymal odontoblasts. It is

Fig. 11. Enameline matrix below pre-enamel zone, showing odontoblastic processes (op) embedded in palisade $(\mathrm{P})$. Non-mineralizing fibrils ( $\mathrm{f}$ ) have polymerized in interpalisadal zone (IP). $\times 17,195$.

Fig. 12. Interpalisadal zone (IP) between adjacent pal isades (P), showing giant fiber ( $\mathrm{gf}$ ) polymerized from amorphous material (a) and unit fibrils (f). Banding periodicity is $17.9 \mathrm{~nm}$. $\times 55,850$.

Fig. 13. Small, dense crystallites of enameline matrix in a mineralizing palisade of Negaprion brevirostris, surrounded by less-dense sheath (arrow) of mineralizing fibrils (tubules). Some fibrils appear to be unmineralized. $\times 91,030$.

Fig. 14. Crystallites of enameline matrix from tooth of Triaenodon obesus, larger than that of the Negaprion specimen utilized for the illustration in Figure 13. Hex agonal shape of larger crystallites is clearly apparent Younger crystallites are surrounded by sheath (arrow); older ones have thinner sheath or have lost it. Crystal lites run in bundles within which they are oriented in the same direction, as in the groups along left and right sides and the curving central group of this micrograph. $\times 88,060$. now recognized that adult amphibian teeth have a covering of true enamel (Gillette, '55; Meredith Smith and Miles, '69, '71). Since the cap layer of larval urodele teeth appears to be different from that of adults, the latter authors theorized that the phylogenetic transition from enameloid to enamel may have come about with the acquisition of metamorphosis in the ontogeny of ancestral amphibians. In contemporary usage the term enameloid is commonly used to denote the cap layer of fish teeth (Moss, '70). In a general sense, the term merely implies that there is a difference between the cap layer of fish teeth and the ectodermal enamel of higher vertebrates. About the nature of the difference it is non-committal. Conceivably the cap layer could be derived from ectoderm, from ectomesenchyme, or from both sources (Schaeffer, '77). Used more specifically, the term enameloid is often used as a substitute for the older terms vitrodentine, mesodermal enamel, and durodentine, denoting the cap layer as modified dentine and therefore of ectomesenchymal origin (Poole, '71; Meredith Smith and Miles, '71; Meinke and Thomson, '83). Some authors consider the cap layer in either elasmobranch or teleost teeth to be of mixed origin, i.e., both epithelial and ectomesenchymal (Shellis and Miles, '74, '76; Shellis, '78; Reif, '79). For some fish groups though, it has been demonstrated that the cap layer in reality is a product of the inner dental epithelium and therefore is true enam. el. Whenever the question of origin remains unsettled, the term enameloid is a useful designation.

Herold ('74) has concluded that the thin surface "enameloid" layer covering teeth of the great northern pike Esox lucius is true ectodermal enamel homologous to that of mammalian enamel. Its matrix is secreted by the inner dental epithelial cells (ameloblasts); its organic component is a granular, homogeneous, non-fibrillar substance; and its mineralized component is calcified through ionic transport of calcium from dental epithelial cells. Enameioid in the angler fish, Lo phius piscatorius, appears to be like that of Esox (Kerebel and Le Cabellec, '80). Garant's (70) opinion that the surface layer of teeth in the blue gourami Helostoma temmincki is modified dentine has led Herold ('74) to speculate that the ability to produce ectodermal enamel may have evolved during "the evolutionary period of the fish." Since Esox and 
Lophius are more primitive than Helostoma, one explanation for the proposed differences in their cap layers might be that primitive actinopterygians possessed ectodermal enamel, whereas some more advanced members of the group may have lost it. On the basis of staining reactions in tissue sections, Shellis (75) has concluded that the mineralizing enameloid matrix of four teleost species (eel,wrasse, bass, and sea bream) receives a contribution of ectodermal protein from the inner dental epithelium.

Ørvig (78a,b,c) has examined the dermal odontodes and teeth of several fossil palaeonisciform actinopterygian fishes, which have cap layers of hypermineralized matrix called ganoin or acrodin. He concludes that although the origin of these layers is still uncertain they resemble the "enameloid" of elasmobranch teeth. They probably received an ectodermal contribution, although they might have received a mesenchymal one as well (ดrvig, '78c).

Considering the Dipnoi and Crossopterygii as sister groups with the Actinopterygii among the Osteichthyes (Gardiner, '73), these groups must have evolved from a common ancestor. Among the crossopterygians the extant actinistian coelacanth Latimeria chalumnae has teeth with ectodermal enamel (Miller, '69; Grady, '70; Shellis and Poole, '78; Smith, '78). The fossil rhipidistian fish Onychodus sp. also had teeth with "pseudoprismatic enamel" considered to be homologous with mammalian enamel (Smith, '79). Dermal denticles in the fossil coelacanth Spermatodus pustulosus (Meinke, '82) were capped with ectodermal enamel. From this emerging pool of information about the enamel layer in crossopterygians, Meinke and Thomson ('83) have concluded that enamel in tetrapods is a primitive character derived from their lobe-finned ancestors. The enamel layer of dipnoan teeth also appears to be derived from inner dental epithelium (Bemis,'84). Available facts point to the supposition that all osteichthyan fish have inherited from a common ancient progenitor the proclivity for coating their teeth with ectodermal enamel. The same holds for Teleostomi in general, since the Acanthodii probably shared common ancestry with the Osteichthyes (Gardiner, '73).

Evidence presented here and elsewhere (Moss, '70; Kemp, '74; Kemp and Park, '74; Kerebel et al., '77; Nanci et al., '83) supports the view that the mineralized components of the shark tooth cap layer are of ectodermal origin and therefore homologous with mammalian enamel. In a study on comparative staining reactions of shark tooth enameloid and bovine enamel, Everett and Miller ('81) found differences sufficient to make their homology questionable. They speculated, however, that there might be an ectodermal contribution to shark tooth enameloid, localizing particularly in the transitional zone between that layer and dentine. Fish at the chondrichthyan level of evolution evidently had already evolved true enamel. Elasmobranch teeth do differ from those of tetrapods by the presence of odontoblastic processes extending into the enamel layer. To connote this histological difference the term enameloid is useful, but it should not imply that the mode of mineralization of the enamel layer necessarily differs in these groups (Kemp, '84).

Was ectodermal enamel an invention of the Chondrichthyes, the first gnathostome vertebrates? Not likely, for the enameloid of dermal odontodes in the earliest known agnathan vertebrates, e.g., the heterostracan ostracoderm Astraspis, appears to have been like that of elasmobranch dermal denticles and teeth (Denison '67; Ørvig, '67; Halstead, '73). The presence of odontoblastic processes penetrating the enamel layer of the odontodes in ostracoderms justifies use of the term enameloid for the reason discussed above, but the source of the mineralizing matrix for this layer was most probably ectoderm rather than mesenchyme. It follows from this interpretation that ectodermal enamel as a type of mineralized tissue ranks with calcified cartilage, bone, and dentine among the most primitive vertebrate hard tissues (Moss, '69, '70, '77; Kemp and Park, '74; Kemp and Westrin, '79).

According to Reif ('79), the enamel layer (enameloid) has evolved structurally from a condition of random orientation of crystals ("single-crystallite enameloid"), as found in ostracoderms and fossil elasmobranchs, to a more highly ordered arrangement ("parallelstructured enameloid") in Euselachii and tetrapods. Nevertheless it is doubtful that the basic homology of the enameloid layer has been altered by such pattern changes. As expressed by Moss ('69), tooth tissues resulting from epithelio-mesenchymal interactions may "differ in detail but utilize similar developmental processes." 


\section{Fibrillogenesis and crystallogenesis in the enameline matrix}

In an earlier publication (Kemp and Park. '74) the significance of three kinds of fibrils in the enamel layer matrix was discussed. Conceivably their protein precursors could be all of ameloblastic origin, all of odontoblastic origin, or mixed in their cells of origin. The fine "unit fibrils" and large, crossbanded "giant" fibers of the interpalisadal zones appear to be successive stages of polymerization of the same precursor. Both may be designated as non-mineralizing fibrils. The fibrils which become mineralized, on the other hand, develop as hollow tubules constituting the sheaths for the mineral crystallites. Whether the non-mineralizing fibrils and the mineralizing tubules are different states of polymerization of a common precursor or develop from two distinct kinds of protein is not known.

Mammalian enamel crystallites develop within a sheath, first described at the electron microscopic level by Scott and Nylen ('62) from decalcified sections. In cross section this sheath is oval, correlated with the observation that mammalian enamel crystallites are greater in width than in thickness (Travis and Glimcher, '64; Jessen, '68). These early workers envisioned the organic matrix as organized into hollow tubules which control the orientation and alignment of crystallites in their prisms and interprisms. Daculsi and Kerebel ('78), however, have questioned the reality of crystallite sheaths, speculating that they could be artifacts of fixation, staining, or electron-beam damage.

Shark tooth enamel crystallites do develop within sheaths. Protein for the tubular sheath is probably amelogenin and/or enamelin, since it is known that these precursors synthesized by mammalian ameloblasts are also produced in shark teeth (Herold et al., '80; Nanci et al., '83). These glycoproteins are probably secreted together with constituents of the basal lamina, including type 4 collagen, laminin and proteoglycans, but fibronectin for the basal lamina is considered to be an odontoblastic product (Slavkin et al., '84). In sharks the basal lamina appears to persist during secretory activity of ameloblasts, whereas in mammalian teeth it characteristically disperses during that period (Kallenbach and Piesco, '78).
Previously it was conjectured that the mineralizing fibrils of shark tooth enamel are a product of ameloblastic secretion, but that the non-mineralizing giant fibers of the interpalisadal zones might be an odontoblastic product (Kemp and Park, '74). Although the banding periodicity of these large fibers (17.9 $\mathrm{nm}$ ) differs markedly from that of conventional collagen $(64.0 \mathrm{~nm})$, it is possible that their precursor is secreted by odontoblasts and as a protein different from that of the mineralizing fibrils segregates to form the interpalisadal zones. A priori, however, one would expect the fibrillar product of odontob. lasts to be collagenous. Kerebel et al. ('77) have shown that collagen fibrils may be present between inner dental epithelium and dental papilla cells at the beginning of amelogenesis, but that they recede toward the interior of the tooth as the mineral layer is deposited. Conventional collagen is no longer present in the mineralizing enamel matrix. Observations in this investigation support the supposition that all three kinds of fibrils in the enameline matrix-unit fibrils, giant fibers, and mineralizing fibrils (tubules)-are products of ameloblastic secretion, polymerizing from a single protein pool or from two segregating pools.

Mammalian amelogenins have a high-molecular-weight precursor of about 40,000 daltons during early amelogenesis, and this may be depolymerized to proteins of lower molecular weight as development proceeds (Fincham et al., '82a,b). Enamelins are evidently more stable and retained longer during tooth maturation. Slavkin et al. ('84) suggest that enamelins are the predominant type of enamel layer proteins in aquatic vertebrates, but that evolution has selected amelogenins as the predominant enameline protein in terrestrial vertebrates. So far enamel layer proteins extracted from elasmobranchs have not been characterized directly.

Apatite minerals typically exhibit a hexagonal mode of mineralization (McConnell, '73). Thus it is not surprising that the hydroxyapatite crystallites of enamel are hexagonal in all vertebrates from sharks to man. In humans the crystallites grow to be about twice as wide as they are thick (Daculsi and Kerebel, '78). They grow in two stages. Initially they grow more rapidly in width than in thickness and during this time are surrounded by a sheath. After a time they appear to lose their sheath, remain about the 
same in width, but continue to grow in thickness. Within prisms crystallites become aligned end-to-end and oriented along the length of the prism (Kerebel et al., '79). Shark tooth enamel crystallites are hexagonal but tend to become equilateral with growth (Kemp and Park, '74; Kerebel et al., '77; Kemp, '84), possibly because of their high fluoride content (Ripa et al., '72; Daculsi and Kerebel, '80). Within palisades crystallites are organized into bundles with individual crystallites running in parallel.

How fibrils of the enameline matrix are related to precursor proteins, in particular the amelogenins and enamelins, remains to be elucidated. In addition, how fibrillogenesis is related to crystallogenesis is still an unsolved mystery (Swancar et al., '71). Fibrillar sheaths appear to direct orientation and alignment of crystallites, but in later stages of crystal growth the organic matrix is degraded (Stack, '67) and may serve only as a vehicle for diffusion of mineral ions in solution. In vitro experiments on the properties of amelogenins and enamelins relative to fibrillogenesis and crystallogenesis should be instructive. Doi et al. ('84) have shown that in culture both of these glycoproteins inhibited growth of seeded apatite crystals. Enamelins were more inhibitory than amelogenins. Further experimental analysis will help to clarify how these proteins control nucleation, early growth and orientation of crystallites.

\section{ACKNOWLEDGMENTS}

This research was supported by NSF Grant 4317, USPHS Grant AM13745, and grants from the University of Michigan Cancer Research Institute. I thank Dr. I. Kaufman Arenberg for donation of Negaprion tissue he obtained during a period of research at the Lerner Laboratory, Bimini, Bahamas in 1972. Triaenodon tissue was obtained by the author at Enewatak Atoll, Marshall Islands, during a research project at the Mid-Pacific Marine Laboratory there in 1972, sponsored by the U.S. Department of Energy under an institutional grant to the Hawaii Institute of Marine Biology, University of Hawaii. I am grateful to Professor John E. Bardach, then Director of the HIMB, for that opportunity. I am especially indebted to Sandra K. Westrin for technical assistance in electron microscopy.

\section{LITERATURE CITED}

Arends, J., W.L. Jongebloed, and J. Schuthof (1983) The ultrastructure of surface enamel in relation to de-and remineralisation. In S. A. Leach and W. M. Edgar (eds): Demineralisation and Remineralisation of the Teeth. Oxford: IRL Press Ltd., pp. 155-163.

Belcourt, A.B., F.G. Fincham, and J.D. Termine (1983) Bovine high molecular weight amelogenin proteins. Calcif. Tissue Int. 35:111-114.

Bemis, W.E. (1984) Morphology and growth of lepidosirenid lungfish tooth plates (Pisces: Dipnoi). J. Morphol. 179:73-93.

Daculsi, G., and B. Kerebel (1978) High-resolution electron microscope study of human enamel crystallites: size, shape, and growth. J. Ultrastruct. Res. 65:163172

Daculsi, G., and L.M. Kerebel (1980) Ultrastructural study and comparative analysis of fluoride content of cnameloid in sea-water and fresh-water sharks. Arch. Oral Biol. 25:145-151.

Denison, R.H. (1967) Ordovician vertebrates from western United States. Fieldiana (Geol.) 16:131-192.

Doi, Y., E.D. Eanes, H. Shimokawa, and J.D. Termine (1984) Inhibition of seed growth of enamel apatite crys. tals by amelogenin and enamelin protein in vitro. $\mathrm{J}$. Dent. Res., 63:98-105.

Everett, M.M., and W.A. Miller (1981) Histochemistry of lower vertebrate calcified structures. I. Enamel of the dogfish Squalus acanthias compared with mammalian enamel and homologous dentine. J. Morphol. 170:95111.

Fincham, A.G., A.B. Belcourt, D.M. Lyaruu, and J.D. Termine (1982a) Comparative protein biochemistry of developing dental enamel matrix from five mammalian species. Calcif. Tissue Int., 34:182-189.

Fincham, A.G., A.B. Belcourt, and J.D. Termine (1982b) Changing patterns of enamel matrix proteins in the developing bovine tooth. Caries Res. 16:64-71.

Fincham, A.G., A.B. Belcourt, J.D. Termine, W.T. Butler, and W.C. Cochran (1983) Amelogenins: sequence homologies in enamel-matrix proteins from 3 mammalian species. Biochem. J. 211:149-154.

Gans, C., and R.G. Northcutt (1983) Neural crest and the origin of vertebrates: a new head. Science 220:268274.

Garant, P.R. (1970) An electron microscopic study of the crystal-matrix relationship in the teeth of the dogfish Squalus acanthias. J. Ultrastruct. Res. 30:441-449.

Garant, P.R., and J. Nalbandian (1968) Observations on the ultrastructure of ameloblasts with special reference to the Golgi complex and related complexes. J. Ultrastruct. Res. 23:427-443.

Gardiner, B.G. (1973) Interrelationships of teleostomes. In P. H. Greenwood, R.S. Miles, and C. Patterson (eds): Interrelationships of Fishes. Zool. J. Linn. Soc., Suppl. 1, Vol. 53. London, New York: Academic Press, pp. 105135.

Gaunt, W.A., and A.E.W. Miles (1967) Fundamental aspects of tooth morphogenesis. In A.E.W. Miles (ed): Structural and Chemical Organization of Teeth. Vol. I. New York: Academic Press, pp. 151-197.

Gillette, R. (1955) The dynamics of continuous succession of teeth in the frog (Rana pipiens). Am. J. Anat. 96:136.

Glimcher, M.J. (1981) On the form and function of bone: from molecules to organs. Wolff's law revisited, 1981. In A. Veis (ed): The Chemistry and Biology of Mineralized Connective Tissues. New York: Elsevier-North Holland, pp. 617-675.

Grady, J.E. (1970) Tooth development in Latimeria chalumnae (Smith). J. Morphol. 132:377-388.

Graver, H.T., R.C. Herold, T.-Y. Chung, P.J. Christner, C. Pappas, and J. Rosenbloom (1978) Immunofluorescent localization of amelogenins in developing bovine teeth. Dev. Biol. 63:390-401. 
Halstead, L.B. (1973) The heterostracan fishes. Biol. Rev. 48:279-332.

Herold, R.C.B. (1974) Ultrastructure of odontogenesis in the pike (Esox lucius). Role of dental epithelium and formation of enameloid layer. J. Ultrastruct. Res. 48:435-454.

Herold, R.C., H.T. Graver, and P. Christner (1980) Immunohistochemical localization of amelogenins in enameloid of lower vertebrate teeth. Science 207:1357-1358.

Jessen, H. (1968) Elliptical tubules as unit structure of forming enamel matrix in the rat. Arch. Oral Biol. 13:351-352.

Kallenbach, E. (1968) Fine structure of rat incisor ameloblasts during enamel maturation. J. Ultrastruct. Res. 22:90-119.

Kallenbach, E., and N.D. Piesco (1978) The changing morphology of the epithelium-mesenchyme interface in the differentiation zone of growing teeth of selected vertebrates and its relationship to possible mechanisms of differentiation. J. Biol. Buccale 6:229-240.

Kemp, N.E. (1974a) Ultrastructure of ameloblasts and enamel in shark teeth. In C.J. Arceneaux (ed): Proc Electron Micr. Soc. America, 32nd Annual Meeting, 1974. Baton Rouge, Louisiana: Claitor's Publ. Div., pp. 76-77 (abstract).

Kemp, N.E. (1974b) Ameloblastic secretion in calcifying teeth of sharks. In J.V. Sanders and D.J. Goodchild (eds): Electron Microscopy 1974. Vol. II Biological. 8th Intern. Cong. Electron Micros. Canberra: Australian Acad. Sci., pp. 458-459 (abstract).

Kemp, N.E. (1984) Organic matrices and mineral crystallites in vertebrate scales, teeth and skeletons. Am. Zool. 24:965-976.

Kemp, N.E., and J.H. Park (1974) Ultrastructure of the enamel layer in developing teeth of the shark Carcharhinus menisorrah. Arch. Oral Biol. 19:633-644.

Kemp, N.E., and S.K. Westrin (1979) Ultrastructure of calcified cartilage in the endoskeletal tesserae of sharks. J. Morphol. 160:75-102.

Kerebel, L.-M., and M.-T. Le Cabellec (1980) Enameloid in the teleost fish Lophius: an ultrastructural study. Cell Tissue Res. 206:211-223.

Kerebel, B., G. Daculsi, and S. Renaudin (1977) Ultrastructure des améloblastes au cours de la formation de l'émailoide des Sélaciens. Biol. Cell. 28:125-130.

Kerebel, B., G. Daculsi, and L.-M. Kerebel (1979) Ultrastructural studies of enamel crystallites. J. Dent. Res. $58: 844-850$.

Kerr, T. (1955) Development and structure of the teeth in the dogfish Squalus acanthias (L.) and Scyliorhinus caniculus (L.). Proc. Zool. Soc. Lond. 125:95-114.

Long, D.M., T.S. Bodenheimer, J.F. Hartmann, and I. Klatzko (1968) Ultrastructural features of the shark brain. Am. J. Anat. 122:209-238.

McConnell, D. (1973) Apatite: Its Crystal Chemistry, Mineralogy, Utilization, and Geologic and Biologic Occurrences, New York: Springer-Verlag.

Meinke, D. (1982) A light microscope and scanning electron microscope study on the dermal skeleton of Spermatodus pustulosus (Pisces: Coelacanthini) and the evolution of the dermal skeleton in coelacanths. J. Paleontol. 56:620-630.

Meinke, D., and K.S. Thomson (1983) The distribution and significance of enamel and enameloid in the dermal skeleton of osteolepiform rhipidistian fishes. $\mathrm{Pa}$ leobiology 9:138

Meredith Smith, M., and A.E.W. Miles (1969) An autoradiographic investigation with the light microscope of proline- $\mathrm{H}^{3}$ incorporation during tooth development in the crested newt (Triturus cristatus). Arch. Oral Biol. 14:479-490.
Meredith Smith, M., and A.E.W. Miles (1971) The ultrastructure of odontogenesis in larval and adult urodeles; differentiation of the dental epithelial cells, $\mathrm{Z}$. Zellforsch. 121:470-498.

Miller, W.A. (1969) Tooth enamel of Latimeria chalumnae (Smith). Nature 221:1244.

Mörnstad, H. (1974) On the histogenesis of shark enamel. Odontolog. Revy 25: 317-325.

Moss, M.L. (1969) Phylogeny and comparative anatomy of oral ectodermal-ectomesenchymal inductive interactions. J. Dent. Res. 48:732-737.

Moss, M.L. (1970) Enamel and bone in shark teeth with a note on fibrous enamel in fishes. Acta Anat. 77:161187.

Moss, M.L. (1977) Skeletal tissues in sharks. Am. Zool. 17:335-342.

Nanci, A., P. Bringas, Jr., N. Samuel, and H.C. Slavkin (1983) Selachian tooth development. 3. Ultrastructural features of secretory amelogenesis in Squalus acanthias. J. Craniofac. Genet. Dev. Biol. 3:53-74.

Northcutt, R.G., and C. Gans (1983) The genesis of neural crest and epidermal placodes; a reinterpretation of vertebrate orjgins. Q. Rev. Biol. 58:1-28.

Orvig, T. (1967) Phylogeny of tooth tissues. Evolution of some calcified tissues in early vertebrates. In A.E.W. Miles (ed): Structural and Chemical Organization of Teeth. Vol. I. New York: Academic Press, pp. 45-110.

Orvig, T. (1977) A survey of odontodes ('dermal teeth') from developmental, structural, functional, and phyletic points of view. In S.M. Andrews, R.S. Miles, and A.D. Walker (eds): Problems in Vertebrate Evolution. New York: Academic Press, pp. 53-75.

Ørvig, T. (1978a) Microstructure and growth of the dermal skeleton in fossil actinopterygian fishes: Birgeria and Scanilepis. Zool. Scripta 7:33-56.

Ørvig, T. (1978b) Microstructure and growth of the dermal skeleton in fossil actinopterygian fishes: Boreosomus, Plegmolepis and Gyrolepis. Zool. Scripta 7:125144.

Ørvig, T. (1978c) Microstructure and growth of the dermal skeleton in fossil actinopterygian fishes: Nephrotus and Colobodus, with remarks on the dentition in other forms. Zool. Scripta 7:297-326.

Poole, D.F.G. (1967) Phylogeny of tooth tissues: enameloid and enamel in recent vertebrates, with a note on the history of cementum. In A.E.W. Miles (ed): Structural and Chemical Organization of Teeth. Vol. I. New York: Academic Press, pp. 111-149.

Poole, D.F.G. (1971) An introduction to the phylogeny of calcified tissues. In A.A. Dahlberg (ed): Dental Morphology and Evolution. Chicago and London: University of Chicago Press, pp. 65-79.

Poole, D.F.G., and M.S. Gillett (1969) Collagen fibers in immature enameloid of dogfish teeth. J. Dent. Res. 48:1119 (abstract).

Reif, W.-E. (1979) Structural convergences between enameloid of actinopterygian teeth and of shark teeth. In O. Johari and R.P. Becker (eds): Scanning Electron Microscopy/1979/II. A.M.F. O'Hare, Illinois: Scanning Electron Microscopy, Inc., pp. 547-554

Reith, E.J. (1967) The early stage of amelogenesis as observed in molar teeth of young rats. J. Ultrastruct. Res. 17:503-526.

Reith, E.J. (1970) The stages of amelogenesis as observed in molar teeth of young rats. J. Ultrastruct. Res. 30:111-151.

Ripa, L.W., A.J. Gwinnett, C. Guzman, and D. Legler (1972) Microstructural and microradiographic qualities of lemon shark enameloid. Arch. Oral Biol. 17:165173. 
Robinson, C., H.D. Briggs, J. Kirkham, and P.J. Atkinson (1983) Changes in the protein components of rat incisor enamel during tooth development. Arch. Oral Biol. 28:993-1000.

Samuel, N., P. Bringas, Jr., V. Santos, A. Nanci, and H.C. Slavkin (1983) Selachian tooth development. 1. Histogenesis, morphogenesis and anatomical features in Squalus acanthias. J. Craniofac. Genet. Dev. Biol. 3:29-42.

Schaeffer, B. (1977) The dermal skeleton in fishes. In S.M. Andrews, R.S. Miles, and A.D. Walker (eds): Problems in Vertebrate Evolution. New York: Academic Press, pp. 25-52.

Scott, D.B., and M.U. Nylen (1962) Organic-inorganic interrelationships in enamel and dentin-a possible key to the mechanism of caries. Int. Dent. J. 12:417442.

Shellis, R.P. (1975) A histological and histochemical study of the matrices of enameloid and dentine in teleost fishes. Arch. Oral Biol. 20:183-188.

Shellis, R.P. (1978) The role of the inner dental epithelium in the formation of the teeth in fish. In P.M. Butler and K.A. Joysey (eds): Development, Function and Evolution of Teeth. London, New York: Academic Press, pp. 30-42.

Shellis, R.P., and A.E.W. Miles (1974) Autoradiographic study of the formation of enameloid and dentine ma trices in teleost fishes using tritiated amino acids. Proc. R. Soc. Lond. (B) 185:51-72.

Shellis, R.P., and A.E.W. Miles (1976) Observations with the electron microscope on enameloid formation in the common eel (Anguilla anguilla: Teleostei). Proc. R. Soc. Lond. (B) 194:253-269.

Shellis, R.P., and D.F.G. Poole (1978) The structure of the dental hard tissues of the coelacanthid fish Latimeria chalumnae Smith. Arch. Oral Biol. 23:1105-1113.

Slavkin, H.C., M. Zeichner-David, D., M. MacDougall, P. Bringas, C. Bessem, and L.S. Honig (1982) Antibodies to murine amelogenins: localization of enamel proteins during tooth organ devleopment in vitro. Differentiation 23:73-82.

Slavkin, H.C., E. Graham, M. Zeichner-David, and W. Hildemann (1983a) Enamel-like antigens in hagfish; possible evolutionary significance. Evolution 37:404412.
Slavkin, H.C., N. Samuel, P. Bringas, Jr., A. Nanci, and V. Santos (1983b) Selachian tooth development. 2. Immunolocalization of amelogenin polypeptides in epithelium during secretory amelogenesis in Squalus acanthias. J. Craniofac. Gen. Dev. Biol, 3:43-52.

Slavkin, H.C., M.L. Snead, M. Zeichner-David, P. Bringas, Jr., and G.L. Greenberg (1984) Amelogenin gene expression during epithelial-mesenchymal interactions. In R.J. Trelstad (ed): The Role of Extracellular Matrix in Development. New York: Alan R. Liss, Inc., pp. 221-253.

Smith, M.M. (1978) Enamel in the oral teeth of Latimeria chalumnae (Pisces: Actinistia): a SEM study. J. Zool. (Lond.) 185:355-370.

Smith, M.M. (1979) SEM of the enamel layer in oral teeth of fossil and extant crossopterygian and dipnoan fishes. In O. Johari and R.P. Becker (eds): Scanning Electron Microscopy/1979/II. A.M.F. O'Hare, Illinois: Scanning Electron Microscopy, Inc., pp. 483-489.

Stack, M.V. (1.967) Chemical organization of the organic matrix of enamel. In A.E.W. Miles (ed): Structural and Chemical Organization of Teeth. Vol. II. New York: Academic Press, pp. 317-346.

Swancar, J.R., D.B. Scott, J.W. Simmelink, and T.J. Smith (1971) The morphology of enamel crystals. In R.W. Fearnhead and M.W. Stack (eds): Tooth Enamel II. Its Composition, Properties and Fundamental Structure. Bristol: John Wright \& Sons Ltd., pp. 233239.

Termine, J.D., A.B. Belcourt, P.J. Christner, K.M. Conn, and M.V.Nylen (1980) Properties of dissociatively extracted fetal tooth matrix proteins. I. Principal molecular species in developing bovine enamel. J. Biol. Chem. 255:9760-9768.

Travis, D.F., and M.J. Glimcher (1964) The structure and organization of, and the relationship between the organic matrix and the inorganic crystals of embryonic bovine enamel. J. Cell Biol. 23:447-497.

Zeichner-David, M., H.C. Slavkin, D.M. Lyaruu, and J.D. Termine (1983) Biosynthesis and secretion of enamel proteins during hamster tooth development. Calcif. Tissue Int. 35:366-371. 